\title{
Autophagy Prevents Oxidative Stress- Induced Loss of Self-Renewal Capacity and Stemness in Human Tendon Stem Cells by Reducing ROS Accumulation
}

\author{
Hua Chen ${ }^{a}$ Heng-an Ge ${ }^{b}$ Gen-bing Wu ${ }^{c}$ Biao Cheng ${ }^{b}$ Yong Lu ${ }^{d}$ Chaoyin Jiang ${ }^{b}$ \\ aDepartment of Orthopedics, Shanghai Jiao Tong University Affiliated Sixth People's Hospital, \\ 'Department of Orthopedics, Shanghai Tenth People's Hospital, Tongji University, School of Medicine, \\ 'Department of Orthopedics, Shanghai Liqun Hospital, dDepartment of Radiology, Ruijin Hospital, \\ School of Medicine, Shanghai Jiao Tong University, Shanghai, China
}

\section{Key Words}

Tendon stem cells $\bullet$ Autophagy $\bullet$ Oxidative stress $\bullet$ Self-renewal $\bullet$ Stemness

\begin{abstract}
Background/Aims: Tendon stem cells (TSCs) exhibit a high self-renewal capacity, multidifferentiation potential, and low immunogenicity; thus, these cells might provide a new cell source for tendon repair and regeneration. TSCs are exposed to increased oxidative stress at tendon injury sites; however, how TSCs maintain their stemness under oxidative stress is not clear. Methods and Results: In this study, we found that $\mathrm{H}_{2} \mathrm{O}_{2}$ treatment increased ROS accumulation in human TSCs (hTSCs) and resulted in loss of self-renewal capacity and stemness, as reflected in reduced colony formation and proliferation, decreased expression of the stemness markers Nanog, Oct-4, NS, and SSEA-4, and impaired differentiation capability. These $\mathrm{H}_{2} \mathrm{O}_{2}$-induced damages were prevented by pretreatment with starvation or rapamycin. Pretreatment with starvation or rapamycin prior to $\mathrm{H}_{2} \mathrm{O}_{2}$ exposure also led to decreased intracellular and mitochondrial ROS accumulation along with increased autophagic activity, as manifested in increased LC3 cleavage, Beclin-1 expression, and GFP-LC3-labeled autophagosome formation. Autophagy inhibition by 3-MA or CQ or by shRNA silencing of Agt-7 or Beclin-1 reduced the protective effects of starvation and rapamycin on $\mathrm{H}_{2} \mathrm{O}_{2}$-treated hTSCs. Conclusion: Thus, the findings of this study suggest that autophagy prevents oxidative stress-induced loss of self-renewal capacity and stemness in hTSCs through suppression of ROS accumulation.




\section{Introduction}

Tendons are fibrous connective tissues that connect muscles to bones. Their primary function is to transmit forces from the corresponding muscle to the skeleton during locomotion, and therefore, they frequently withstand mechanical loading. Tendon injuries from overuse cause pain and motion impairment, and can progress into osteoarthritis and disability, and eventually the need for joint replacement [1]. Recently, tendon stem cells (TSCs) have been isolated from human and several other species [2-4]. These cells can proliferate and differentiate into different cell types such as tenocytes, chondrocytes, osteocytes, and adipocytes in vitro and form tendon-like, cartilage-like, and bone-like tissues in vivo [4]. In addition, rat TSCs have been reported to participate in tendon repair after injury through migration, proliferation, and activation of tenogenesis [5]. Thus, TSCs might provide a new cell source for tendon repair and regeneration. Understanding the mechanisms that regulate TSC proliferation and maintenance may help guide the development of stem cell-based therapies for tendinopathy.

Autophagy is a natural, destructive mechanism that allows the orderly degradation and recycling of dysfunctional cellular components [6]. Autophagy is activated by various intrinsic and extrinsic cellular stresses, such as starvation, reactive oxygen species (ROS) accumulation, and hypoxia, and plays a crucial role in maintaining cellular homeostasis under these stress conditions. Accumulating evidence has revealed that autophagy plays a key role in the control of self-renewal and stemness of stem cells [7, 8]. Studies have shown that autophagic activity is constitutively high in mesenchymal, hematopoietic, dermal, and epidermal stem cells, and is downregulated after induced differentiation to a basal level similar to that observed in most somatic cells [9-11]. It has also been reported that autophagy promotes self-renewal and maintains stemness of mesenchymal stem cells during hypoxia, starvation, or irradiation [12-15]. Based on these results, we wondered whether autophagy is also involved in the homeostatic control of TSCs under stress conditions.

It has been well recognized that mechanical overloading induces cellular stresses such as oxidative stress and endoplasmic reticulum (ER) stress in tenocytes, which contribute to the development of tendinitis and tendon degeneration $[16,17]$. However, how these cellular stresses impact TSC maintenance and function has not been reported. In this study, we found that $\mathrm{H}_{2} \mathrm{O}_{2}$ treatment of human TSCs (hTSCs) resulted in ROS accumulation and loss of selfrenewal capacity, cell stemness, and differentiation capability. Starvation and the mTOR inhibitor rapamycin increased autophagic activity, reduced ROS generation, and maintained self-renewal capacity, cell stemness, and differentiation capability in $\mathrm{H}_{2} \mathrm{O}_{2}$-treated hTSCs. Moreover, these protective effects of starvation and rapamycin were curtailed by autophagy inhibition. These results indicate that autophagy protected hTSCs against oxidative stressinduced damages through suppression of ROS accumulation.

\section{Materials and Methods}

\section{Cell culture}

hTSCs were isolated from supraspinatus tendon of four adult donors (26 to 34 years old) undergoing arthroscopic rotator cuff repair as described previously [18]. The protocol for obtaining the tendon samples was approved by the Research Ethics Committee of Shanghai Sixth People's Hospital (Shanghai, China). The cells were cultured at $37^{\circ} \mathrm{C}, 5 \% \mathrm{CO}_{2}$ in a humidified incubator as previously described [19]. Cells at passage four after isolation were used in all experiments.

\section{$\mathrm{H}_{2} \mathrm{O}_{2}$ treatment}

Untransfected or transfected hTSCs were incubated with different concentrations of $\mathrm{H}_{2} \mathrm{O}_{2}(0.25,0.5$, and $0.75 \mathrm{mM}$ ) for up to $24 \mathrm{~h}$. To test the effects of starvation, cells were incubated in serum free medium for $6 \mathrm{~h}$ prior to $\mathrm{H}_{2} \mathrm{O}_{2}$ treatment. To test the effects of rapamycin, $\mathrm{N}$-acetylcysteine (NAC), 3-methyladenine (3$\mathrm{MA}$ ), or chloroquine (CQ), cells were incubated with $200 \mathrm{nM}$ rapamycin, $2 \mathrm{mM} \mathrm{NAC,} 2 \mathrm{mM}$ 3-MA, or $10 \mu \mathrm{M}$ $\mathrm{CQ}$ alone or in combination for $2 \mathrm{~h}$ prior to $\mathrm{H}_{2} \mathrm{O}_{2}$ treatment. 


\section{Cellular Physiology Cell Physiol Biochem 2016;39:2227-2238 \begin{tabular}{l|l|l} 
and Biochemistry Published onlIne: November 07, 2016 & $\begin{array}{l}\text { (c) } 2016 \text { The Author(s). Published by S. Karger AG, Basel } \\
\text { www.karger.com/cpb }\end{array}$ \\
\hline
\end{tabular}}

Chen et al.: Autophagy Protects TSCs Against Oxidative Stress

\section{Colony formation assay}

After treatment, untransfected or transfected hTSCs were seeded in culture dishes at 50 cells $/ \mathrm{cm}^{2}$ and incubated at $37^{\circ} \mathrm{C}, 5 \% \mathrm{CO}_{2}$ for 14 days. The cells were washed with PBS, fixed in methanol, and stained with $2 \%$ crystal violet for $10 \mathrm{~min}$. Colonies of more than 50 cells were counted under a microscope. All experiments were performed in triplicate.

\section{Cell proliferation assay}

Cell proliferation was determined using the Cell Counting Kit-8 (CCK-8) (Dojindo, Kumamoto, Japan). Briefly, hTSCs were seeded in 96-well plates at $5 \times 10^{3}$ cells/well. Cells were subsequently incubated with $\mathrm{H}_{2} \mathrm{O}_{2}$ at indicated concentrations for $0,3,6,9$, and $12 \mathrm{~h}$, respectively, with or without pretreatment with starvation or rapamycin. Cell viability was determined using the CCK-8 assay following manufacturer's instructions. The absorbance at $450 \mathrm{~nm}$ was recorded on a Synergy HT microplate reader (Bio-Tek, Vinooski, VT, USA). All experiments were performed in triplicate.

\section{Quantitative real-time PCR ( $q R T-P C R)$}

Total RNA was extracted using Trizol reagent (Invitrogen, Carlsbad, USA). Complementary DNA (cDNA) was synthesized by reverse transcribing $1 \mu \mathrm{g}$ RNA using the RevertAid RT-PCR system (Fermentas, Pittsburgh, PA, USA). qRT-PCR was performed using Maxima SYBR Green qPCR Master Mix (Applied Biosystems, Carlsbad, CA, USA) on a Stratagene Mx3000P RT-PCR system following manufacturer's instructions. Gene specific primers for Nanog, nucleostemin (NS), Oct-4, SSEA-4, PPAR- $\gamma$, Sox-9, and Runx-2 were synthesized according to previously published sequences [14, 20]. Data were normalized to GAPDH. All experiments were performed in triplicate.

\section{Differentiation assays}

The adipogenic and osteogenic differentiation capabilities of hTSCs were assessed as previously described [19]. Briefly, to assess the adipogenic differentiation capability, cells were cultured in adipogenic differentiation medium (mesenchymal stem cell adipogenesis kit, Millipore) for up to 14 days following manufacturer's instructions. At day 14, accumulation of lipid droplets was examined microscopically with Oil Red $O$ (Millipore) staining. To assess the osteogenic differentiation capability, cells were cultured in osteogenic differentiation medium (DMEM-low glucose, 10\% FBS, 4 mM L-glutamine, $0.1 \mu$ M dexamethasone, $50 \mu \mathrm{g} / \mathrm{ml}$ L-ascorbic acid-2-phosphate, $10 \mathrm{mM} \beta$-glycerophosphate, $1 \%$ antibiotic-antimycotic mix) for up to 14 days. At day 14, calcium deposition was examined using Alizarin Red solution (Millipore) following manufacturer's instructions. The chondrogenic differentiation capability of hTSCs was assessed according to previously published procedures [21]. Briefly, cells were cultured in chondrogenic differentiation medium (DMEM, 20\% FBS, $2 \mathrm{mM}$ L-glutamine, $100 \mathrm{U} / \mathrm{ml}$ penicillin, $100 \mathrm{mg} / \mathrm{ml}$ streptomycin) for up to 14 days. At day 14, chondrogenesis was examined using Alcian Blue (Millipore) staining. In addition, the mRNA levels of the adipogenic marker PPAR $\gamma$, the osteogenic marker Runx-2, and the chondrogenic marker Sox-9 after 0, 7 , and 14 days of differentiation were determined using qRT-PCR.

\section{Western blot analysis}

Cells were lysed in RIPA buffer and centrifuged for $10 \mathrm{~min}$ at $4^{\circ} \mathrm{C}$. The supernatants were collected and the protein concentrations were determined using the BCA Protein Assay Kit (Pierce, Rockford, IL, USA). Samples (20 $\mu \mathrm{g}$ of total protein) were separated by 12\% SDS-PAGE and transferred onto PVDF membranes. After blocking in 5\% nonfat milk for $2 \mathrm{~h}$, the membranes were incubated with primary antibodies against Nanog, NS, Oct-4, SSEA-4, LC3, Beclin-1, and Atg-7, respectively, at $4^{\circ} \mathrm{C}$ overnight. All primary antibodies were from Novus Biologicals, Inc. (Littleton, CO, USA). The membranes were subsequently incubated with horseradish peroxidase-conjugated secondary antibody (Dako, Carpinteria, CA, USA) and protein bands were detected by enhanced chemiluminescence (Beyotime, Shanghai, China). Data were normalized to GAPDH. All experiments were performed in triplicate.

Short hairpin RNA (shRNA) transfection

shRNAs targeting Atg-7 (Atg-7-shRNA, 5'-CCAAGGTCAAAGGACGAAGAT-3') and Beclin-1 (Beclin-1shRNA, 5'-GCAGATGAGGAA GATCGCCTT-3') and a scrambled shRNA (SCR-shRNA) used as negative control were inserted into the pGCL-GFP lentiviral expression vector (Shanghai GeneChem, Shanghai, China). The 


\section{Cellular Physiology Cell Physiol Biochem 2016;39:2227-2238 and Biochemistry Published \begin{tabular}{l|l} 
DOI: 10.1159/000447916 & $\begin{array}{l}\text { C } 2016 \text { The Author(s). Published by S. Karger AG, Basel } \\
\text { www.karger.com/cpb }\end{array}$
\end{tabular}}

Chen et al.: Autophagy Protects TSCs Against Oxidative Stress

recombinant virus was packaged using the Lentivector Expression System (Shanghai GeneChem). Cells were infected for $48 \mathrm{~h}$ and GFP expression was examined under a fluorescence microscope.

ROS generation

To assess mitochondria-derived ROS, cells were stained with MitoSOX (2.5 $\mu \mathrm{M}$, Sigma) for $10 \mathrm{~min}$ at $37^{\circ} \mathrm{C}$ and subjected to FACS analysis on a flow cytometer (FACS Aria, BD, NJ, USA). To assess intracellular peroxide accumulation, cells were stained with DCF-DA ( $5 \mathrm{mM}$, Sigma) for $30 \mathrm{~min}$ at $37^{\circ} \mathrm{C}$. Cell nuclei were counter-stained with Hoechst 33258 (1 mM, Sigma) for $20 \mathrm{~min}$ and cells were analyzed under a fluorescence microscope. All experiments were performed in triplicate.

\section{Detection of autophagosomes with GFP-LC3 labeling}

hTSCs were transfected with $1 \mu \mathrm{g}$ of GFP-LC3 cDNA construct (Addgene, Cambridge, MA, USA) for $4 \mathrm{~h}$ using Lipofectamine 2000 (Invitrogen). The transfected cells were seeded in six-well plates $\left(2 \times 10^{5}\right.$ cells/well) and cultured overnight. On the next day, cells were treated with $0.5 \mathrm{mM} \mathrm{H}_{2} \mathrm{O}_{2}$ for $24 \mathrm{~h}$ with or without pretreatment with starvation or rapamycin. Untreated cells were included as control. GFP-LC3labeled vacuoles (autophagosomes) were counted under an Olympus microscope equipped with a coolsnap camera. All experiments were performed in triplicate.

\section{Statistical analysis}

All results are presented as the mean \pm SD (standard deviation). Data analysis was performed using GraphPad Prism 5 software (GraphPad Software Inc., La Jolla, USA). One-way analysis of variance (ANOVA) was employed to interpret differences between groups. Single comparison was conducted with Student's $t$ test and multiple comparisons were performed using Tukey's HSD post hoc test. Differences with $P<0.05$ were considered statistically significant.

\section{Results}

$\mathrm{H}_{2} \mathrm{O}_{2}$ impaired hTSC self-renewal capacity and stemness

We first examined the effects of $\mathrm{H}_{2} \mathrm{O}_{2}$ treatment on hTSC self-renewal capacity. As shown in Fig. 1A, treating hTSCs with $\mathrm{H}_{2} \mathrm{O}_{2}$ at concentrations of 0.5 and $0.75 \mathrm{mM}$ for $24 \mathrm{~h}$ significantly impaired the colony formation capacity of these cells. Similarly, profound inhibition of cell proliferation was observed at these $\mathrm{H}_{2} \mathrm{O}_{2}$ concentrations (Fig. 1B). We subsequently examined the effects of $\mathrm{H}_{2} \mathrm{O}_{2}$ on the expression of the cell stemness markers Nanog, Oct-4, NS, and SSEA-4. As shown in Figure 1C and 1D, treatment with $0.5 \mathrm{mM} \mathrm{H}_{2} \mathrm{O}_{2}$ for $24 \mathrm{~h}$ resulted in significant decreases in the mRNA and protein expression of these stemness markers. To examine the effects of $\mathrm{H}_{2} \mathrm{O}_{2}$ on hTSC differentiation into adipocytes, chondrocytes, and osteocytes, cells were incubated with $0.5 \mathrm{mM} \mathrm{H}_{2} \mathrm{O}_{2}$ or vehicle alone for $24 \mathrm{~h}$ and cultured in adipogenic, chondrogenic, and osteogenic differentiation media, respectively, for 14 days. Oil Red 0, Alcian Blue, and Alizarin Red S staining were used to assess lipid accumulation, cartilage matrix formation, and calcium deposition, respectively. Compared with control, $\mathrm{H}_{2} \mathrm{O}_{2}$-treated cells showed markedly reduced lipid accumulation, cartilage matrix formation, and calcium deposition 14 days after differentiation initiation (Fig. 1E). In addition, $\mathrm{H}_{2} \mathrm{O}_{2}$ treated cells exhibited significantly lower expression of the adipogenic marker PPAR- $\gamma$, the chondrogenic marker Sox-9, and the osteogenic marker Runx-2, respectively, during the 14day period of differentiation (Fig. 1F). These results indicated that increased oxidative stress impaired the self-renewal capacity, stemness, and differentiation potential of hTSCs.

\section{Starvation and rapamycin protected hTSCs against $\mathrm{H}_{2} \mathrm{O}_{2}$-induced damages}

To test the effects of starvation and rapamycin, hTSCs were incubated in serum free medium or treated with $200 \mathrm{nM}$ rapamycin for $2 \mathrm{~h}$ prior to $24 \mathrm{~h}$ exposure to $0.5 \mathrm{mM} \mathrm{H}_{2} \mathrm{O}_{2}$. As shown in Fig. 2A and 2B, cells pretreated with starvation/rapamycin prior to $\mathrm{H}_{2} \mathrm{O}_{2}$ treatment showed more robust colony formation capacity and more rapid proliferation compared with cells treated with $\mathrm{H}_{2} \mathrm{O}_{2}$ alone. The mRNA and protein expression of the stemness 


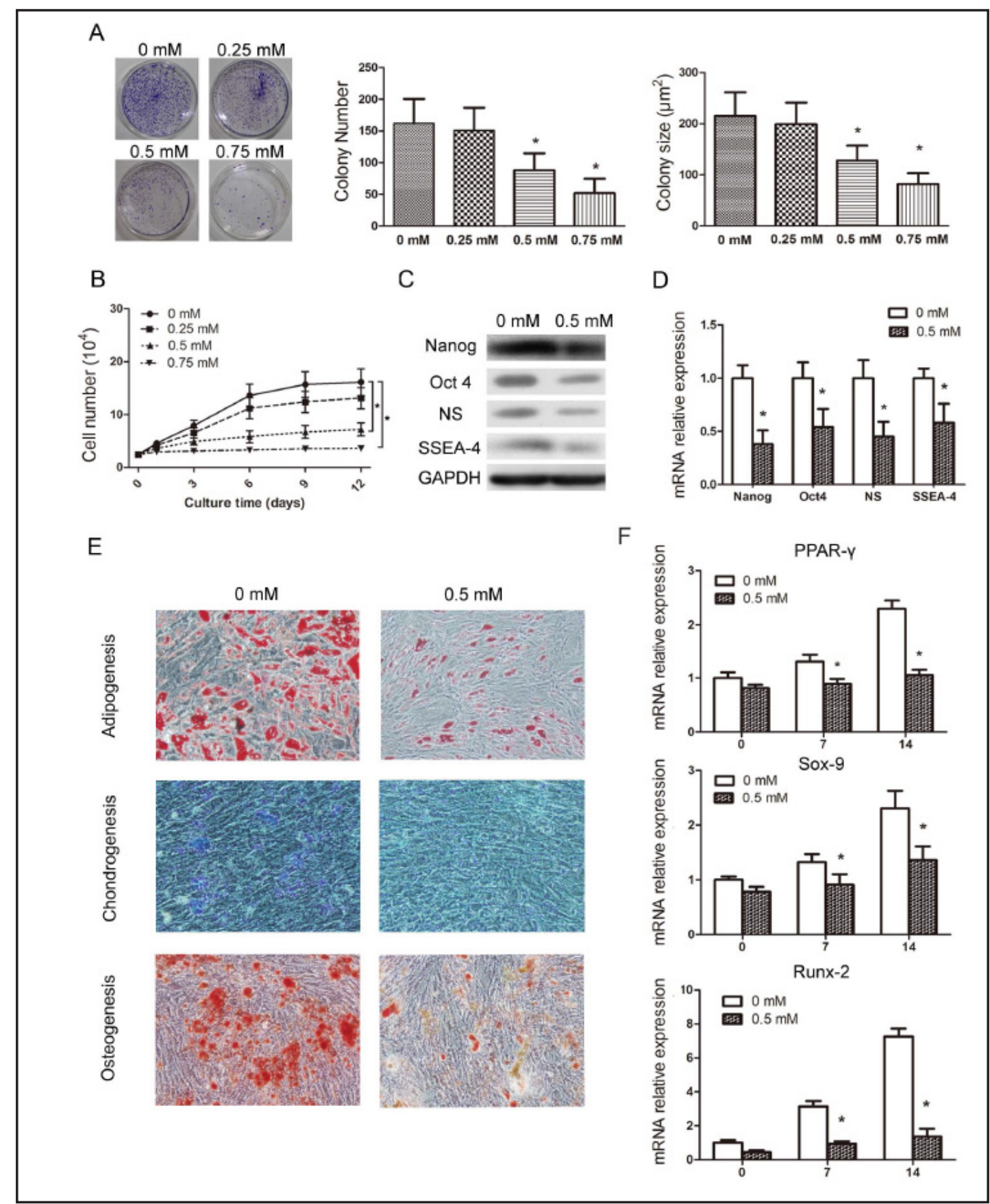

Fig. 1. $\mathrm{H}_{2} \mathrm{O}_{2}$ impaired hTSC self-renewal capacity, stemness, and differentiation potential. (A) hTSCs were treated with $0.25,0.5$, and $0.75 \mathrm{mM} \mathrm{H}_{2} \mathrm{O}_{2}$ or vehicle alone for $24 \mathrm{~h}$. Self-renewal capacity was assessed by colony formation assay. (B) hTSCs were treated with $0.25,0.5$, and $0.75 \mathrm{mM} \mathrm{H}_{2} \mathrm{O}_{2}$ or vehicle alone for up to $12 \mathrm{~h}$. Cell proliferation was determined by the CCK-8 assay at indicated time points. (C, D) hTSCs were treated with $0.5 \mathrm{mM} \mathrm{H}_{2} \mathrm{O}_{2}$ or vehicle alone for $24 \mathrm{~h}$. The protein and mRNA levels of the stemness markers Nanog, Oct-4, NS, and SSEA-4 were determined by western blotting (C) and qRT-PCR (D), respectively. (E, F) hTSCs were treated with $0.5 \mathrm{mM} \mathrm{H}_{2} \mathrm{O}_{2}$ or vehicle alone for $24 \mathrm{~h}$. Cells were subsequently cultured in the adipogenic, chondrogenic, and osteogenic differentiation medium, respectively, for up to 14 days. (E) At day 14 after differentiation induction, lipid accumulation, cartilage matrix formation, and calcium deposition were assessed by Oil Red O, Alcian Blue, and Alizarin Red S staining, respectively. (F) At days 0, 7, and 14 after differentiation induction, the mRNA levels of the adipogenic marker PPAR- $\gamma$, the chondrogenic marker Sox9 , and the osteogenic marker Runx- 2 were determined by qRT-PCR. $\mathrm{n}=3,{ }^{*} p<0.05$ vs. vehicle alone ( $0 \mathrm{mM}$ ). 


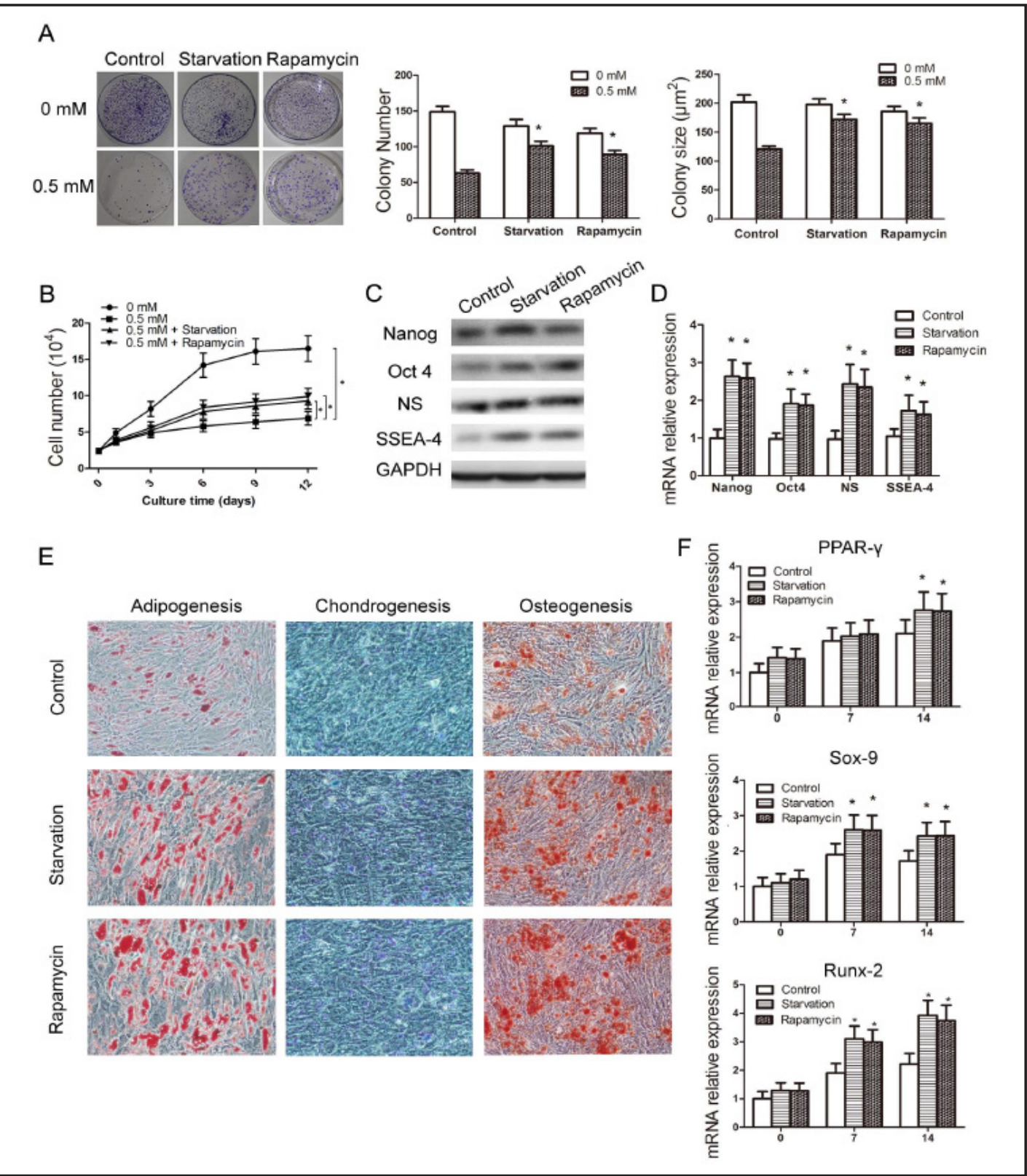

Fig. 2. Pretreatment with starvation/rapamycin maintained self-renewal capacity, stemness, and differentiation potential in $\mathrm{H}_{2} \mathrm{O}_{2}$-treatedhTSCs. (A) hTSCs were treated with $0.5 \mathrm{mM} \mathrm{H}_{2} \mathrm{O}_{2}$ or vehicle alone for $24 \mathrm{~h}$ with or without pretreatment with starvation/rapamycin. Self-renewal capacity was assessed by colony formation assay. (B) hTSCs were treated with $0.5 \mathrm{mM} \mathrm{H}_{2} \mathrm{O}_{2}$ for up to $12 \mathrm{~h}$ with or without pretreatment with starvation/rapamycin. Untreated cells were included for comparison. Cell proliferation was determined by the CCK-8 assay. (C, D) hTSCs were treated with $0.5 \mathrm{mM} \mathrm{H}_{2} \mathrm{O}_{2}$ for $24 \mathrm{~h}$ with or without pretreatment with starvation/rapamycin. The protein and mRNA levels of the stemness markers Nanog, Oct-4, NS, and SSEA-4 were determined by western blotting (C) and qRT-PCR (D), respectively. (E, F) hTSCs were treated with 0.5 $\mathrm{mM} \mathrm{H}_{2} \mathrm{O}_{2}$ for $24 \mathrm{~h}$ with or without pretreatment with starvation/rapamycin. Cells were subsequently cultured in the adipogenic, chondrogenic, and osteogenic differentiation medium, respectively, for up to 14 days. (E) At day 14 after differentiation induction, lipid accumulation, cartilage matrix formation, and calcium deposition were assessed by Oil Red O, Alcian Blue, and Alizarin Red S staining, respectively. (F) At days 0, 7, and 14 after differentiation induction, the mRNA levels of the adipogenic marker PPAR- $\gamma$, the chondrogenic marker Sox-9, and the osteogenic marker Runx- 2 were determined by qRT-PCR. $\mathrm{n}=3,{ }^{*} p<0.05$ vs. 0.5 mM $\mathrm{H}_{2} \mathrm{O}_{2}$ alone.

\section{KARGER}




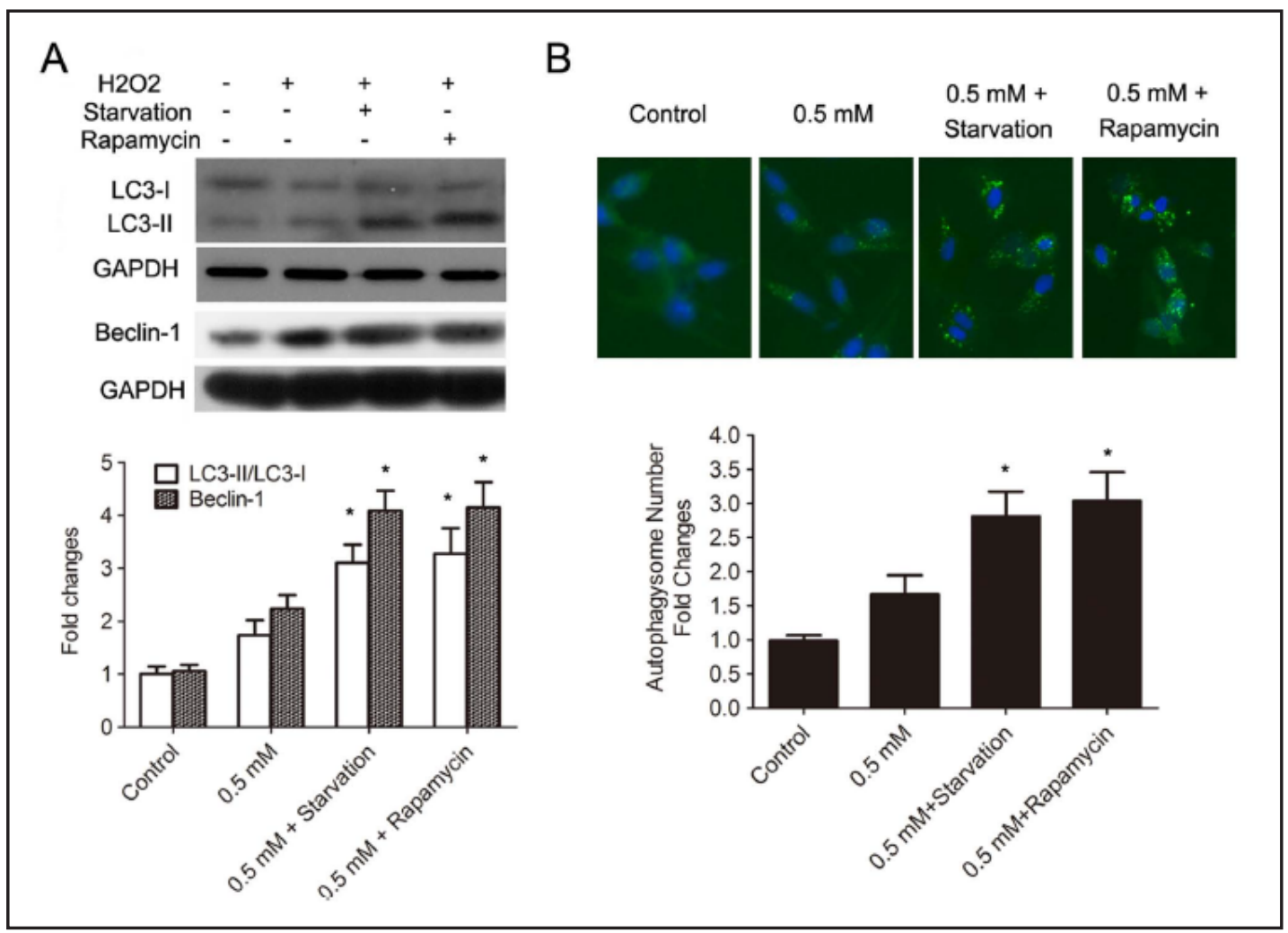

Fig. 3. Pretreatment with starvation/rapamycin activated autophagy in $\mathrm{H}_{2} \mathrm{O}_{2}$-treated hTSCs. (A) hTSCs were treated with $0.5 \mathrm{mM} \mathrm{H}_{2} \mathrm{O}_{2}$ for $24 \mathrm{~h}$ with or without pretreatment with starvation/rapamycin. Untreated cells were included for comparison. The protein levels of the autophagic markers LC3-I, LC3-II, and Beclin-1 were determined by western blotting. (B) hTSCs were transiently transfected with GFP-LC3 and subsequently treated with $0.5 \mathrm{mM} \mathrm{H}_{2} \mathrm{O}_{2}$ for $24 \mathrm{~h}$ with or without pretreatment with starvation/rapamycin. Transfected but untreated cells were included for comparison. GFP-LC3-labeled vacuoles (puncta) were detected by fluorescence imaging. $\mathrm{n}=3,{ }^{*} p<0.05$ vs. $0.5 \mathrm{mM} \mathrm{H}_{2} \mathrm{O}_{2}$ alone.

markers Nanog, Oct-4, NS, and SSEA-4 were also increased when cells were pretreated with starvation/rapamycin (Fig. 2C and 2D). Moreover, pretreated cells showed markedly increased lipid accumulation, cartilage matrix formation, and calcium deposition after 14 days of adipogenic, chondrogenic, and osteogenic differentiation, respectively (Fig. 2E). Consistent with these results, the lineage-specific markers were also upregulated in the pretreated cells during differentiation (Fig. 2F). These data indicated that starvation and rapamycin protected hTSCs from $\mathrm{H}_{2} \mathrm{O}_{2}$-induced damages in self-renewal capacity, stemness, and differentiation capability.

Starvation and rapamycin activated autophagy in $\mathrm{H}_{2} \mathrm{O}_{2}$-treated hTSCS

Starvation and rapamycin are well-known inducers of autophagy. To assess cellular autophagic activity, we determined the protein levels of the autophagic markers L3-I, L3-II, and Beclin-1. The conversion of soluble L3-I to lipid-bound L3-II as well as increased Beclin-1 expression are indicators of autophagosome formation. As shown in Fig. 3A, pretreatment with starvation/rapamycin significantly increased the LC3-II/L3-I ratio as well as Beclin-1 protein level in $\mathrm{H}_{2} \mathrm{O}_{2}$-treated hTSCs. To directly visualize autophagosome formation, cells were transiently transfected with GFP-LC3 prior to $\mathrm{H}_{2} \mathrm{O}_{2}$ exposure. The GFP-LC3-labeled vacuoles were detected by fluorescence imaging. The results showed that cells pretreated with starvation/rapamycin prior to $\mathrm{H}_{2} \mathrm{O}_{2}$ exposure displayed a greater number of GFP-LC3labeled vacuoles compared with cells treated with $0.5 \mathrm{mM} \mathrm{H}_{2} \mathrm{O}_{2}$ alone (Fig. 3B). These data indicated that starvation and rapamycin activated autophagy in $\mathrm{H}_{2} \mathrm{O}_{2}$-treated hTSCs. 
A

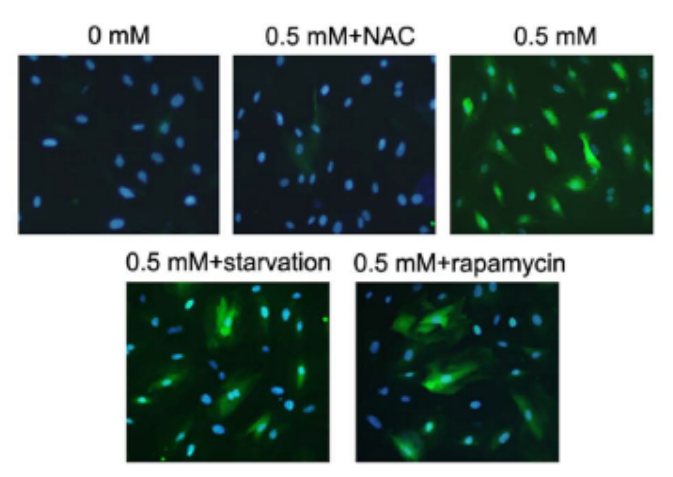

B
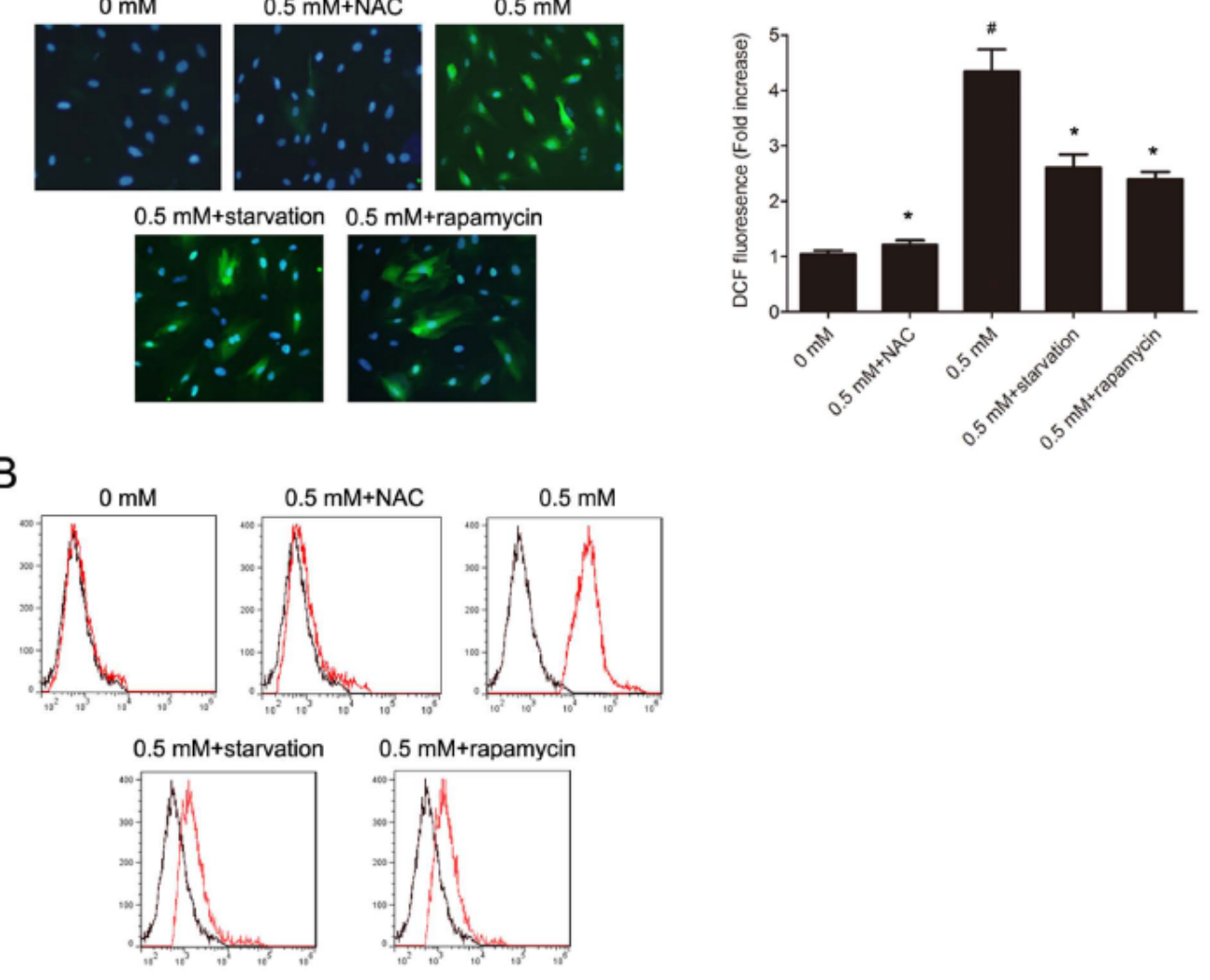

Fig. 4. Pretreatment with starvation/rapamycin suppressed ROS accumulation in $\mathrm{H}_{2} \mathrm{O}_{2}$-treated hTSCs. hTSCs were treated with $0.5 \mathrm{mM} \mathrm{H}_{2} \mathrm{O}_{2}$ for $24 \mathrm{~h}$ with or without pretreatment with starvation/rapamycin/NAC. Untreated cells were included for comparison. (A) Intracellular ROS levels were determined by fluorescence imaging with DCF-DA staining. $\mathrm{n}=3$, ${ }^{*} p<0.05$ vs. $0.5 \mathrm{mM} \mathrm{H}_{2} \mathrm{O}_{2}$ alone, ${ }^{*} p<0.05$ vs. untreated cells $(0 \mathrm{mM})$.

(B) Mitochondrial ROS levels were assessed by flow cytometry with MitoSOX staining.

Starvation and rapamycin suppressed ROS accumulation in $\mathrm{H}_{2} \mathrm{O}_{2}$-treated hTSCS

Exposure to $\mathrm{H}_{2} \mathrm{O}_{2}$ leads to increased intracellular ROS generation. Excessive ROS can cause significant damages in cell structures and functions. Autophagy is often triggered by ROS [22], and conversely, autophagy can contribute to reduce oxidative stress by engulfing and degrading oxidized cellular components [23]. To investigate the mechanisms underlying the protective effects of starvation and rapamycin on $\mathrm{H}_{2} \mathrm{O}_{2}$-treated hTSCs, we assessed intracellular ROS levels using the fluorescent probe dichlorofluorescin diacetate (DCF-DA). We also determined mitochondrial ROS levels using MitoSOX, a fluorogenic dye for highly selective detection of superoxide in the mitochondria of live cells. As shown in Fig. 4A and 4B, treating hTSCs with $0.5 \mathrm{mM} \mathrm{H}_{2} \mathrm{O}_{2}$ for $24 \mathrm{~h}$ drastically increased intracellular and mitochondrial ROS levels. These $\mathrm{H}_{2} \mathrm{O}_{2}$-induced ROS increases were prevented by pretreatment with the antioxidant NAC as well as starvation/rapamycin (Fig. 4A and 4B). These findings suggested that suppression of ROS accumulation contributed to the protective effects of starvation and rapamycin on $\mathrm{H}_{2} \mathrm{O}_{2}$-treated hTSCs.

The protective effects of starvation and rapamycin on $\mathrm{H}_{2} \mathrm{O}_{2}$-treated hTSCs were inhibited by autophagy blockage

To confirm that autophagy contributed to the maintenance of self-renewal and stemness in $\mathrm{H}_{2} \mathrm{O}_{2}$-treated hTSCs, we tested the effects of autophagy inhibition by chemical inhibitors 


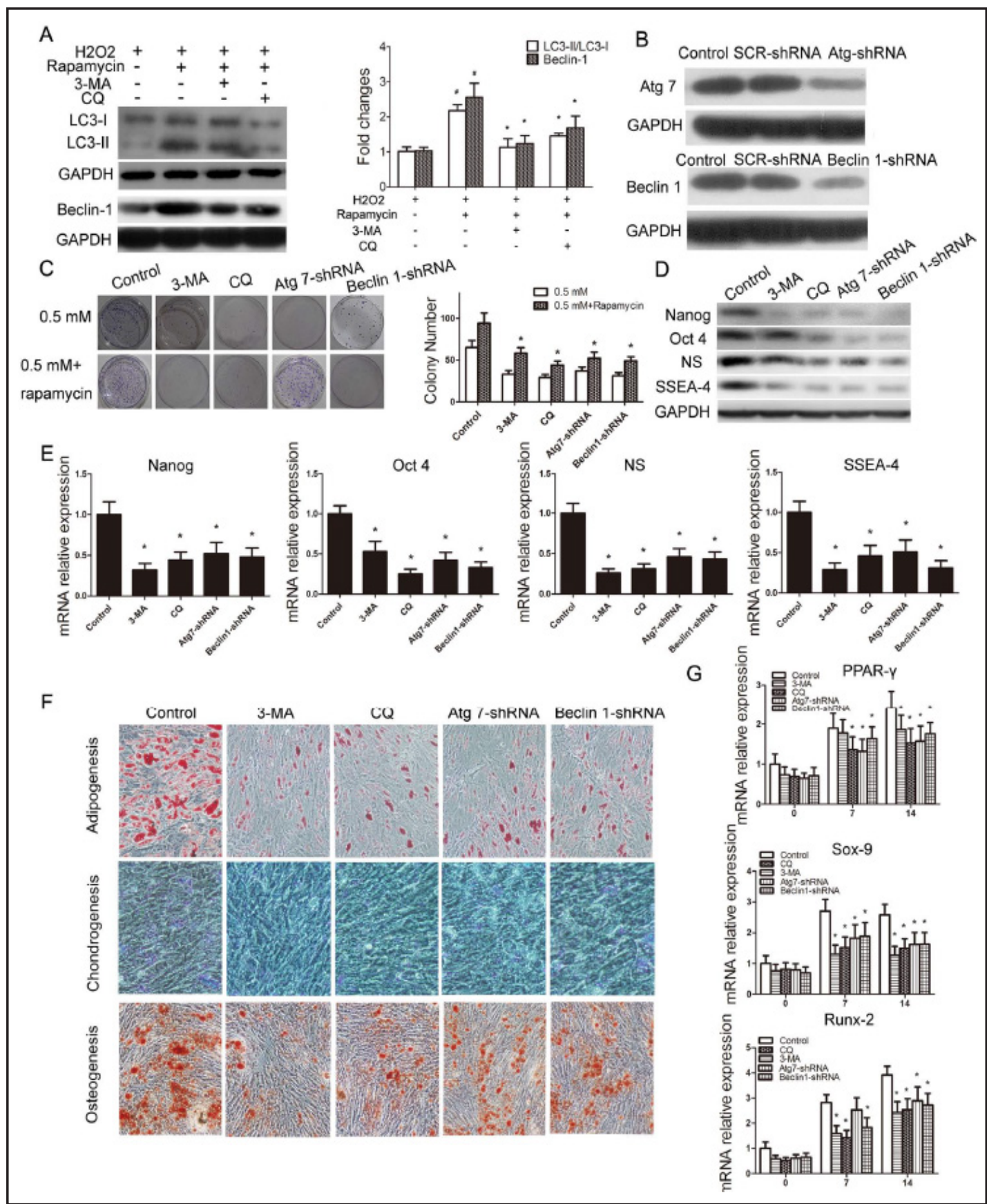

Fig. 5. Autophagy blockage inhibited the protective effects of starvation and rapamycin on $\mathrm{H}_{2} \mathrm{O}_{2}$-treated hTSCs. (A) hTSCs were pretreated with rapamycin together with 3-MA or CQ as indicated prior to $24 \mathrm{~h}$ exposure to $0.5 \mathrm{mM} \mathrm{H}_{2} \mathrm{O}_{2}$. The protein levels of LC3-I, LC3-II, and Beclin-1 were determined by western blotting. (B) hTSCs were transiently transfected with SCR-shRNA, Atg-7-shRNA, or Beclin-1-shRNA. Untransfected cells were included for comparison. The protein levels of Atg-7 and Beclin-1 were determined by western blotting. (C-G) hTSCs were transfected and/or pretreated as indicated prior to $24 \mathrm{~h}$ exposure to $0.5 \mathrm{mM}$ $\mathrm{H}_{2} \mathrm{O}_{2}$. (C) Self-renewal capacity was assessed by colony formation assay. (D, E) The protein and mRNA levels of the stemness markers Nanog, Oct-4, NS, and SSEA-4 were determined by western blotting (D) and qRTPCR (E), respectively. (F, G) The adipogenic, chondrogenic, and osteogenic differentiation were assessed by Oil Red O, Alcian Blue, and Alizarin Red S staining, respectively, at day 14 after differentiation induction (F) and the PPAR- $\gamma$, Sox-9, and Runx-2 mRNA levels were determined by qRT-PCR at days 0, 7, and 14 after differentiation induction (G). $\mathrm{n}=3,{ }^{*} p<0.05$ vs. $0.5 \mathrm{mM} \mathrm{H}_{2} \mathrm{O}_{2}+$ rapamycin, ${ }^{\#} p<0.05$ vs. $0.5 \mathrm{mM} \mathrm{H}_{2} \mathrm{O}_{2}$ alone.

\section{KARGER}


or gene silencing. 3-MA or CQ are widely used cell-permeable small molecule autophagy inhibitors. As shown in Fig. 5A, the addition of 3-MA or CQ to rapamycin during pretreatment significantly reduced LC3-II/LC3-I ratio and Beclin- 1 protein level in $\mathrm{H}_{2} \mathrm{O}_{2}$-treated hTSCs. Compared with cells pretreated with rapamycin alone, cells pretreated with rapamycin together with 3-MA or CQ exhibited reduced colony formation capacity (Fig. 5C), decreased mRNA and protein expression of the stemness markers Nanog, Oct-4, NS, and SSAE-4 (Fig. 5D and 5E), as well as impaired adipogenic, chondrogenic, and osteogenic differentiation (Fig. 5F and 5G). Atg-7 and Beclin-1 are essential protein mediators of autophagy. We subsequently tested the effects of autophagy blockage by Atg-7 or Beclin-1 silencing. The results showed that silencing of Atg-7 or Beclin-1 by shRNA transfection prior to rapamycin pretreatment led to similar decreases in colony formation capacity, stemness marker expression, and differentiation capabilities in $\mathrm{H}_{2} \mathrm{O}_{2}$-treated cells (Fig. 5B-G). Together, these data provided evidence that autophagy played a critical role in the maintenance of self-renewal, stemness, and differentiation potential of $\mathrm{H}_{2} \mathrm{O}_{2}$-treated hTSCs.

\section{Discussion}

Tendon and ligament injuries are common in occupational and athletic settings. Recovery is often slow and financially demanding. With the recent advances in stem cell biology, research on the use of stem cells to repair tendon and cartilage injuries is gaining momentum, with the majority using mesenchymal stem cells or embryonic stem cells [24, 25]. Recently isolated TSCs exhibit a high self-renewal capacity, multi-differentiation potential, and low immunogenicity; thus, these cells might provide a new cell source for tendon regeneration [26]. Loss of cell self-renewal capacity and pluripotency is a major obstacle to stem cellbased therapies. Considering that TSCs implanted in injury sites would be exposed to various cellular stresses, we studied the effects of increased oxidative stress on hTSCs in vitro. We found that $\mathrm{H}_{2} \mathrm{O}_{2}$-treated hTSCs exhibited increased ROS accumulation along with reduced colony formation and proliferation, decreased expression of the stemness markers Nanog, Oct-4, NS, and SSEA-4, and impaired differentiation capability. Thus, hTSC maintenance under stress conditions such as increased oxidative stress may be a challenge to overcome in TSC-based therapy. It has been reported that autophagy is a mechanism used by stem cells to maintain self-renewal and stemness under various external insults [12-14]. Starvation and the mTOR inhibitor rapamycin are well established activators of autophagy. Thus, we examined the effects of starvation and rapamycin on hTSCs exposed to $\mathrm{H}_{2} \mathrm{O}_{2}$. Pretreating hTSCs with starvation or rapamycin effectively prevented $\mathrm{H}_{2} \mathrm{O}_{2}$-induced impairment in selfrenewal capacity, stemness marker expression, and differentiation capability. These protective effects were accompanied by activated autophagic activity as reflected in increased LC3 cleavage, Beclin-1 expression, and GFP-LC3-labeled autophagosome formation. Moreover, autophagy inhibition by 3-MA or CQ, or by shRNA silencing of Agt-7 or Beclin-1 reduced the protective effects of starvation and rapamycin on $\mathrm{H}_{2} \mathrm{O}_{2}$-treated hTSCs. These data indicated that autophagy contributed to the maintenance of self-renewal capacity, stemness, and differentiation capability of hTSCs under oxidative stress. Considering that autophagy often functions as an anti-oxidant by clearing away oxidized cellular components, we detected ROS levels in hTSCs. Similar to that observed with the antioxidant NAC, pretreatment with starvation and rapamycin led to significantly decreased intracellular and mitochondrial ROS levels in $\mathrm{H}_{2} \mathrm{O}_{2}$-treated hTSCs. These results suggested that starvation and rapamycin protected hTSCs against oxidative stress-induced damages by inducing autophagy, thereby reducing ROS accumulation.

Increasing evidence has revealed that autophagy regulates stem cell self-renewal capacity, differentiation, and somatic reprogramming [7, 27]. To our knowledge, this is the first report on the role of autophagy in homeostatic control of TSC proliferation, stemness, and differentiation. Interestingly, a recent study has shown that hTSCs cultured in hypoxic 


\section{Cellular Physiology Cell Physiol Biochem 2016;39:2227-2238 \begin{tabular}{l|l} 
DOI: 10.1159/000447916 & $\begin{array}{l}\text { O 2016 The Author(s). Published by S. Karger AG, Basel } \\
\text { www.karger.com/cpb }\end{array}$
\end{tabular}

conditions exhibited increased cell proliferation and stem cell marker expression in vitro and formed more tendon-like structures in tendon-derived matrix in vivo [20]. Considering that hypoxia is a well-recognized autophagy inducer, we think that autophagy likely played a role in the maintenance of hTSCs under hypoxic conditions as well. To take one step further, autophagy might also play a critical role in the maintenance of hTSCs exposed to other stresses that frequently occur at tendon injury sites, such as ER stress and inflammation. Further research is required to find out whether these speculations are correct.

In brief, the findings of this study show that autophagy protects hTSCs from oxidative stress-induced damages by curtailing ROS accumulation. Whether autophagy inducers such as starvation and rapamycin can promote hTSC tenogenesis in vivo waits further investigation.

\section{Acknowledgments}

The study was supported by grants from Natural Science Foundation of China (No. 81372005 and 81372000 ) and Project of Shanghai Jiao Tong University Medical-Engineering Cross Fund (YG2013MS25).

\section{Disclosure Statement}

The authors declare that they have no conflict of interest.

\section{References}

$>1$ Nourissat G, Berenbaum F, Duprez D: Tendon injury: From biology to tendon repair. Nat Rev Rheumatol 2015;11:223-233.

-2 Bi Y, Ehirchiou D, Kilts TM, Inkson CA, Embree MC, Sonoyama W, Li L, Leet AI, Seo BM, Zhang L, Shi S, Young MF: Identification of tendon stem/progenitor cells and the role of the extracellular matrix in their niche. Nat Med 2007;13:1219-1227.

-3 Rui YF, Lui PP, Li G, Fu SC, Lee YW, Chan KM: Isolation and characterization of multipotent rat tendonderived stem cells. Tissue Eng Part A 2010;16:1549-1558.

4 Zhang J, Wang JH: Characterization of differential properties of rabbit tendon stem cells and tenocytes. BMC Musculoskelet Disord 2010;11:10.

5 Tan Q Lui PP, Lee YW: In vivo identity of tendon stem cells and the roles of stem cells in tendon healing. Stem Cells Dev 2013;22:3128-3140.

6 Kobayashi S: Choose delicately and reuse adequately: The newly revealed process of autophagy. Biol Pharm Bull 2015;38:1098-1103.

7 Vessoni AT, Muotri AR, Okamoto OK: Autophagy in stem cell maintenance and differentiation. Stem Cells Dev 2012;21:513-520.

-8 Guan JL, Simon AK, Prescott M, Menendez JA, Liu F, Wang F, Wang C, Wolvetang E, Vazquez-Martin A, Zhang J: Autophagy in stem cells. Autophagy 2013;9:830-849.

-9 Oliver L, Hue E, Priault M, Vallette FM: Basal autophagy decreased during the differentiation of human adult mesenchymal stem cells. Stem Cells Dev 2012;21:2779-2788.

10 Salemi S, Yousefi S, Constantinescu MA, Fey MF, Simon HU: Autophagy is required for self-renewal and differentiation of adult human stem cells. Cell Res 2012;22:432-435.

11 Cheng Y, Wang B, Zhou H, Dang S, Jin M, Shi Y, Hao L, Yang Z, Zhang Y: Autophagy is required for the maintenance of liver progenitor cell functionality. Cell Physiol Biochem 2015;36:1163-1174.

12 Lee Y, Jung J, Cho KJ, Lee SK, Park JW, Oh IH, Kim GJ: Increased scf/c-kit by hypoxia promotes autophagy of human placental chorionic plate-derived mesenchymal stem cells via regulating the phosphorylation of mtor. J Cell Biochem 2013;114:79-88. 


\section{Cellular Physiology Cell Physiol Biochem 2016;39:2227-2238

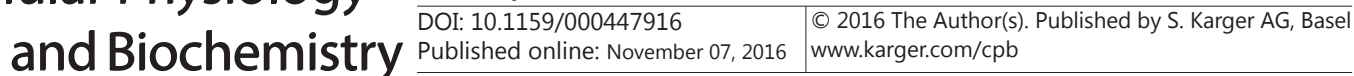 \\ Chen et al.: Autophagy Protects TSCs Against Oxidative Stress}

13 Zhang Q, Yang YJ, Wang H, Dong QT, Wang TJ, Qian HY, Xu H: Autophagy activation: A novel mechanism of atorvastatin to protect mesenchymal stem cells from hypoxia and serum deprivation via amp-activated protein kinase/mammalian target of rapamycin pathway. Stem Cells Dev 2012;21:1321-1332.

14 Hou J, Han ZP, Jing YY, Yang X, Zhang SS, Sun K, Hao C, Meng Y, Yu FH, Liu XQ, Shi YF, Wu MC, Zhang L, Wei LX: Autophagy prevents irradiation injury and maintains stemness through decreasing ros generation in mesenchymal stem cells. Cell Death Dis 2013;4:e844.

15 Song BQ, Chi Y, Li X, Du WJ, Han ZB, Tian JJ, Li JJ, Chen F, Wu HH, Han LX, Lu SH, Zheng YZ, Han ZC: Inhibition of notch signaling promotes the adipogenic differentiation of mesenchymal stem cells through autophagy activation and pten-pi3k/akt/mtor pathway. Cell Physiol Biochem 2015;36:1991-2002.

-16 Archambault JM, Wiley JP, Bray RC: Exercise loading of tendons and the development of overuse injuries. A review of current literature. Sports Med 1995;20:77-89.

17 Yuan J, Murrell GA, Trickett A, Wang MX: Involvement of cytochrome c release and caspase-3 activation in the oxidative stress-induced apoptosis in human tendon fibroblasts. Biochim Biophys Acta 2003;1641:3541.

18 Randelli P, Conforti E, Piccoli M, Ragone V, Creo P, Cirillo F, Masuzzo P, Tringali C, Cabitza P, Tettamanti G, Gagliano N, Anastasia L: Isolation and characterization of 2 new human rotator cuff and long head of biceps tendon cells possessing stem cell-like self-renewal and multipotential differentiation capacity. Am J Sports Med 2013;41:1653-1664.

19 Randelli P, Menon A, Ragone V, Creo P, Bergante S, Randelli F, De Girolamo L, Alfieri Montrasio U, Banfi G, Cabitza P, Tettamanti G, Anastasia L: Lipogems product treatment increases the proliferation rate of human tendon stem cells without affecting their stemness and differentiation capability. Stem Cells Int 2016;2016:4373410.

20 Zhang J, Wang JH: Human tendon stem cells better maintain their stemness in hypoxic culture conditions. PLoS One 2013;8:e61424.

21 Tao X, Liu J, Chen L, Zhou Y, Tang K: Egr1 induces tenogenic differentiation of tendon stem cells and promotes rabbit rotator cuff repair. Cell Physiol Biochem 2015;35:699-709.

22 Scherz-Shouval R, Elazar Z: Regulation of autophagy by ros: Physiology and pathology. Trends Biochem Sci 2011;36:30-38.

23 Li L, Tan J, Miao Y, Lei P, Zhang Q: Ros and autophagy: Interactions and molecular regulatory mechanisms. Cell Mol Neurobiol 2015;35:615-621.

24 MacLean S, Khan WS, Malik AA, Snow M, Anand S: Tendon regeneration and repair with stem cells. Stem Cells Int 2012;2012:316281.

25 Ramdass B, Koka PS: Ligament and tendon repair through regeneration using mesenchymal stem cells. Curr Stem Cell Res Ther 2014;10:84-88.

26 Zhang Q, Cheng B: Tendon-derived stem cells as a new cell source for tendon tissue engineering. Front Biosci (Landmark Ed) 2013;18:756-764.

27 Pan H, Cai N, Li M, Liu GH, Izpisua Belmonte JC: Autophagic control of cell 'stemness'. EMBO Mol Med 2013;5:327-331. 


\section{Erratum}

In the original article by Chen et al. entitled "Autophagy Prevents Oxidative Stress- Induced Loss of SelfRenewal Capacity and Stemness in Human Tendon Stem Cells by Reducing ROS Accumulation" [Cell Physiol Biochem 2016;39:2227-2238 (DOI: 10.1159/000447916)] there are few corrections, as following:

- The affiliation of the corresponding author Chaoyin Jiang is "a" not "b"

- The name of "Gen-bin Wu" was misspelled as "Gen-bing Wu"

The authors names with affiliations are correctly here:

Hua Chen ${ }^{\mathrm{a}}$ Heng-an Ge $\mathrm{b}^{\mathrm{b}}$ Gen-bin $\mathrm{Wu}^{\mathrm{c}} \quad$ Biao Cheng ${ }^{\mathrm{b}} \quad{\text { Yong } \mathrm{Lu}^{\mathrm{d}} \quad \text { Chaoyin Jianga }}^{\mathrm{a}}$

${ }^{a}$ Department of Orthopedics, Shanghai Jiao Tong University Affiliated Sixth People's Hospital, ${ }^{b}$ Department of Orthopedics, Shanghai Tenth People's Hospital, Tongji University, School of Medicine, 'Department of Orthopedics, Shanghai Liqun Hospital, dDepartment of Radiology, Ruijin Hospital, School of Medicine, Shanghai Jiao Tong University, Shanghai, China

The authors terribly apologized for this carelessness. 